\title{
The Consequences of Zakat for Capital Accumulation
}

\author{
D.H. Norulazidah P.H. Omar Ali \\ University of Exeter \\ Gareth D. Myles* \\ University of Exeter and Institute for Fiscal Studies
}

June 1, 2010

\begin{abstract}
The payment of zakat by the owners of wealth is one of the five pillars of Islam. Many countries operate with no enforcement of the obligation to pay, making zakat a form of voluntary redistribution. We analyze how zakat affects capital accumulation in a model that explicitly recognizes the voluntary nature of zakat. The voluntary payment is modelled using both warm-glow and social custom frameworks. These are embedded within an overlapping generations model with heterogenous consumers and endogenous population growth. The results show that zakat can raise the capital-labor ratio when it is motivated by the warm-glow but welfare can be non-monotonic in the strength of the warm-glow. In the social custom model reduced participation can lead to a reduced capital-labor ratio as the rate of zakat is increased.

JEL classification codes: E62, H21, P51
\end{abstract}

Acknowledgements: Thanks are due to Ted Bergstrom, Nigar Hashimzade, seminar participants in Exeter, participants in the Singapore conference on Leadership, Altruism, and Social Organization, and the Associate Editor and referee.

${ }^{*}$ Corresponding author. Address: Department of Economics, Streatham Court, Rennes Drive, Exeter EX4 4PU, United Kingdom. E-mail: G.D.Myles@exeter.ac.uk 


\section{Introduction}

Paying zakat is one of the five pillars of Islam stated in the Koran. The payment of zakat is a religious obligation and must be fulfilled by Muslims who own wealth above the minimum threshold. Al-Qardawi (1997) argues that zakat is not just a form of worship but also that the receipt of the proceeds of zakat is a right of the poor. There are two types of zakat: zakat-al-fitr and zakat-al-mal. Zakat-alfitr must be paid for charity at the end of Ramadhan (Zayas, 1960). We focus on zakat-al-mal which is the zakat on wealth. This is levied on different types of wealth at a benchmark rate of 2.5 percent. Zakat on wealth must be paid by Muslims who own wealth above the nisab, the minimum exemption limit, and must be paid annually. The goal of zakat is to redistribute wealth from the owners of nisab (the non-poor) to the non-owners of nisab (the poor).

The institution of zakat can be viewed as a system of voluntary redistribution supported by religious obligation. It represents an alternative institutional form to redistribution through statutory taxes and transfers. Interesting questions are therefore raised concerning the economic consequences of this institution.

There have been several studies of the economic effect of zakat (Siddiqi 1979, Rahman 2003, Kuran 2006). Most Islamic economists argue that zakat has a positive effect on the economy. It is generally concluded that the effect of the implementation of zakat is to increase aggregate demand, increase the capital stock, and raise economic growth. There are two separate arguments underlying these claims. The first observes that zakat is a transfer of wealth from the rich to the poor, so if the poor have a higher marginal propensity to consume than the rich then aggregate demand will rise. The second is the claim that zakat payers will increase their saving ratio in order to avoid the depletion of wealth due to the payment of zakat. Embedding these arguments within a static Keynesian model leads to the conclusion that the increase in saving will ultimately be matched by an increase in investment (Kahf 1980, Khan 1984). The level of output therefore rises in equilibrium. Some of the limitations of this reasoning are identified by Iqbal (1985) who observed that the consumptions effects of transfers of wealth from the rich to the poor could cancel unless a Keynesian aggregate consumption function was assumed.

There are two further significant limitations of this previous literature. First, the models used are static so provide a poor framework for addressing the effects of zakat on capital accumulation and growth. In order to see the overall effects of zakat on an economy's capital accumulation and consumption, it is necessary to consider how the economy is affected in the long run. Thus, we choose to analyze zakat within an overlapping generations model in order to derive long-run implications for capital accumulation. Second, the models do not incorporate the motive for paying zakat within the analysis of consumption and saving decisions. The economic representation of this motive has to be a key component of the analysis.

The motivation for paying zakat is important because it is a religious obligation rather than a statutory duty. In other words, zakat is not a tax but is instead a voluntary contribution to wealth redistribution. We consider two dif- 
ferent explanations for why such a voluntary contribution is made. The first is to model the reward from making the payment as a form of warm-glow (Andreoni, 1990). The alternative is to model the religious obligation behind contributions to zakat as a social custom. We discuss the relative merits of these two approaches in more detail below. In our modelling we also assume that the growth rate of population is endogenous. In particular, we assume the growth rate of the poor population is dependent upon the income level of the poor. This assumption can be motivated by the argument that both fertility and the survival rates of infants are dependent on income. In any case, this mechanism provides an interesting feedback from zakat to the dynamic evolution of the economy. One of the arguments of Malthus against the English Poor Law was that support for the poor was self-defeating: support raised the population which, in turn, reduced the real wage. The process of zakat is different. Zakat is provided out of wealth, so an increase in support for the poor is obtained from greater wealth accumulation. Since this raises the stock of capital it does not follow that the real wage must fall.

The analysis explores the economic consequences of the institution of zakat employing standard economic models drawn from the literature on voluntary contribution. The results demonstrate that the institution of zakat can increase the capital-labor ratio in the model that we analyze if contribution is explained by a warm-glow. The results for the social custom model are not so promising for the institution. As the rate of zakat is increased the model predicts a fall in the capital-labor ratio through decreased participation in the social custom.

Section 2 reviews the operation of zakat and the modelling of voluntary contributions. Section 3 presents the overlapping generations economy we use to study zakat and characterizes dynamic equilibrium and the steady-state. Section 4 describes the different forms of preference we employ to explain voluntary provision of zakat. The preferences are placed within the overlapping generations economy in Section 5 and a simulation analysis undertaken. Conclusions are given in Section 6.

\section{Operation and Modelling of Zakat}

Zakat is not purely an act of worship. Apart from its religious objectives zakat also has the socioeconomic objective of reducing inequality in the distribution of wealth between the rich and the poor (Ahmad, 1980). The Koran permits a zakat payment to be made directly to recipients or through a zakat collection authority (Mannan, 1986). Both centralized (or obligatory) and decentralized (or voluntary) modes of zakat administration are permitted. Malaysia, Saudi Arabia, and Pakistan are among the countries where zakat is administered by the state (Kuran, 2006). In many other countries the state is not directly involved.

Zakat payments on wealth are made on an annual basis. The forms of wealth that are zakatable, and the ratios of zakat payment on each, were not fully specified in the Koran. The rates of zakat payment, time of payment, the nisab, and the method of organizing and administering zakat collection 
and distribution were adopted through the practice or sayings of the Prophet Muhammad. According to Shaik (1979, cited by Zaman 1980) a majority of Islamic jurists agree on the rates in Table 1 and the zakatable assets in Table 2.

Table 1: Rates of zakat

\begin{tabular}{|c|c|}
\hline Item & Rate \\
\hline On all types of wealth & $2.5 \%$ \\
\hline Mines and treasure troves & $20 \%$ \\
\hline Produce from irrigated land & $5 \%$ \\
\hline Produce from unirrigated land & $10 \%$ \\
\hline Animals & $1.5 \%-2.5 \%$ \\
\hline
\end{tabular}

Table 2: Types of zakatable assets, nisab, and rates

\begin{tabular}{|c|c|c|}
\hline $\begin{array}{c}\text { Types of wealth } \\
\text { or asset }\end{array}$ & Nisab & Rate \\
\hline Gold & 85 grams of gold & $2.5 \%$ of the value \\
\hline Silver & 595 grams of silver & $2.5 \%$ of the value \\
\hline $\begin{array}{c}\text { Cash in hand, stocks, } \\
\text { bonds, trading } \\
\text { goods, or any } \\
\text { other liquid asset }\end{array}$ & $\begin{array}{c}\text { Amount equivalent to } \\
85 \text { grams of gold }\end{array}$ & $2.5 \%$ of the value \\
\hline Agricultural produce & 653 kg per harvest & $5 \%$ (irrigated land) \\
$10 \%$ (non-irrigated land)
\end{tabular}

Islamic jurists have different opinions about which sources of wealth should be subject to zakat. Kahf (1997) noted three fiqhi views, or opinions, on zakat collection. The narrow opinion includes agricultural products, gold and silver (except for personal use), trading goods, short-term net returns, and cash in hand. This is the most agreed upon method of zakat calculation. The middle opinion includes all types of assets listed in the narrow opinion plus earnings on fixed assets, as well as wages, salaries, and professional incomes. The latter is controversial in relation to the zakatability of new forms of wealth. The third opinion includes items under the narrow and middle opinions plus fixed assets, which are assets used to generate income. This would include assets such as buildings, furniture, machinery, and containers. However, a majority of contemporary scholars believe business fixed assets should be exempt from zakat.

The distribution of the proceeds of zakat is clearly targeted to eight zakat recipients in the Koran. As mentioned in Surah 9 verses 58-60:

"A collected sadaqa is for the poor, the destitute, those who collect it, reconciling people's hearts, freeing slaves, those in debt, spending in the Way of Allah and wayfarers..."

Five of the eight eligible recipients of zakat proceeds are considered to fall under the poor category (Al-Abdin, 1997): the poor, the destitute, slaves, those in debt, and wayfarers. 
The question of whether zakat is a tax has been widely debated. Economists such as Kahf (1999), Kamali (1999), and Kuran (2006) have referred to zakat as a tax. Certainly, zakat shares with taxation the aim of achieving economic and social objectives. Where they differ is that payment of tax is mandatory whereas the payment of zakat is a religious obligation. It is important to observe that there is limited evidence of state enforcement of zakat payment even where legislation permits this. Hence, in most countries zakat is voluntary and is made either directly to the poor or to a zakat collection authority. A further difference is that tax rates can be changed as part of fiscal policy whereas the rate of zakat is fixed through religious ruling. Finally, the recipients of the proceeds of zakat are specifically defined whereas hypothecation is rarely used for taxation. However, zakat shares with taxation the property that it results in the transfer of purchasing power from one economic agent to another. It should therefore be possible to explore the economic effects of zakat using the same tools as applied to taxation provided that the motives for giving zakat are adequately represented.

According to Chapra (1992), the payment of zakat should be voluntary but with the state able to enforce payment if it wishes to do so. Since there are many countries in which zakat is not enforced but the level of payment is significant, it is necessary to consider explanations of such voluntary giving. In doing this we are seeking an economic representation of the religious motives that drive the payment of zakat. Alexander et al. (1997) suggested that people give because they expect gratitude and because of religious commitment. The two representations we consider, the warm-glow and social custom models, can be seen as formalizations of these explanations.

Andreoni $(1989,1990)$ motivated giving through the derivation of internal satisfaction; this satisfaction has become known as the warm-glow. In the warmglow model the amount given is an argument of the utility function alongside other consumption goods and is chosen as part of the utility maximization process. In our context the warm-glow can be viewed as the pleasure derived from fulfillment of religious duties or from a more literal promise of future reward. Examples of support for the latter interpretation can be found in Islamic teaching:

Allah's Apostle said, "If one give in charity what equals one datefruit from the honestly-earned money and Allah accepts only the honestly earned money - Allah takes it in His right (hand) and then enlarges its reward for that person (who has given it), as anyone of you brings up his baby horse, so much so that it becomes as big as a mountain. ${ }^{11}$

As zakat is a religious obligation, we would expect failure to meet this to result in a utility loss. This motivates our second way of modelling zakat. The social custom model developed in Myles and Naylor (1996) captures the idea that there is a loss of welfare if an accepted form of behavior is not followed.

\footnotetext{
${ }^{1}$ darulislam.info/Hadith_Bukhari-index-action-viewcat-cat-24.html
} 
In our model the accepted form of behavior is to meet religious obligations and provide zakat. Hence, an owner of nisab who does not give zakat loses utility from the social custom but can take advantage of higher disposable income. The idea that there is a loss from breaking the social custom is made very clear:

Allah's Apostle said, "Whoever is made wealthy by Allah and does not pay the Zakat of his wealth, then on the Day of Resurrection his wealth will be made like a bald-headed poisonous male snake with two black spots over the eyes. The snake will encircle his neck and bite his cheeks and say, 'I am your wealth, I am your treasure.'"I2

\section{Economy}

The debate in previous literature has focused upon how the institution of zakat affects capital accumulation and economic growth. To address these questions we extend the standard overlapping generations model to incorporate two types of consumer and include endogenous population growth. This section describes a general version of the economy we consider. The general model encompasses the special cases that arise when we specialize preferences to represent alternative motives for providing zakat.

Each consumer lives for two periods and works only in the first period of life. In the second period of life each consumer is retired. Labor is supplied inelastically and is measured in efficiency units. A rich consumer is able to supply a greater number of efficiency units of labor than a poor consumer. The labor income of a rich consumer is divided between consumption and saving. In the second period of life savings are divided between consumption and the payment of zakat on accumulated wealth. A poor consumer receives labor income in the first period of life and payments of zakat in both periods. The poor do not save, so all their income is consumed in the period in which it is received. It is assumed that all the poor are identical (except for date of birth). The rich can differ in the quantity of labor they are able to supply and in attitude toward the payment of zakat.

A rich consumer born in period $t$ is described by a vector of characteristics $\sigma$. The elements of this vector are made precise in the different models of preferences. Across the population of the rich $\sigma$ has a time-invariant distribution $f(\sigma)$ with strictly positive support on $\Sigma=[\underline{\sigma}, \bar{\sigma}]$. Hence, $\int_{\underline{\sigma}}^{\bar{\sigma}} f(\sigma) d \sigma=1$. A consumer with characteristics $\sigma$ has consumption level in the first period of life $x_{t, t}^{r}(\sigma)$ and in the second period $x_{t, t+1}^{r}(\sigma)$. Savings are denoted $s_{t}(\sigma)$ and labor supply $\ell^{r}(\sigma)$. Savings at time $t$ provide the wealth on which zakat is paid in period $t+1$. Zakat is a voluntary payment out of accumulated wealth so it is always made in the second period of life. Hence, denote the zakat payment of a rich consumer born in $t$ by $z_{t+1}(\sigma)$.

\footnotetext{
${ }^{2}$ darulislam.info/Hadith_Bukhari-index-action-viewcat-cat-24.html
} 
A poor consumer born in period $t$ works in the first period of life and earns labor income $\ell^{p} w_{t}$. They receive a payment of zakat, $\zeta_{t}$. The sum of labor income and zakat is assumed to be insufficient to finance saving; hence, consumption in the first period of life is

$$
x_{t, t}^{p}=\ell^{p} w_{t}+\zeta_{t} .
$$

In the second period of life each poor consumer receives a payment of zakat, $\zeta_{t+1}$. Consumption in the second period of life is

$$
x_{t, t+1}^{p}=\zeta_{t+1} .
$$

At the beginning of each period a new generation consisting of poor and rich consumers is born. At time $t$ the number of rich consumers born is $N_{t}^{r}$ and the number of poor consumers is $N_{t}^{p}$. The population growth rate of the rich is denoted $n^{r}$ and the population growth of the poor is $n_{t}^{p}$. The value of $n^{r}$ is exogenous and constant, but $n_{t}^{p}$ is endogenous. The dynamics of population for the two groups are given by

$$
N_{t+1}^{r}=\left(1+n^{r}\right) N_{t}^{r}
$$

and

$$
N_{t+1}^{p}=\left(1+n_{t}^{p}\right) N_{t}^{p} .
$$

We assume that zakat is paid equally to both young and old poor. A more sophisticated structure could be assumed but would be unlikely to significantly alter the results. ${ }^{3}$ We also assume, as is standard in tax models, that there is no administrative cost in collecting or distributing zakat. Let $Z_{t}=N_{t-1}^{r} \int_{\underline{\sigma}}^{\bar{\sigma}} z_{t}(\sigma) f(\sigma) d \sigma$ be the total contributed in zakat in period $t$. By construction, the zakat received at time $t$ by each member of the poor is given by

$$
\zeta_{t}=\frac{Z_{t}}{N_{t}^{p}+N_{t-1}^{p}} .
$$

We adopt a Malthusian model of population growth for the poor under which the growth rate, $n_{t}^{p}$, is determined by fertility and survival. We assume that these are related to the level of first-period income which is the sum of labor income plus the amount of zakat received. Since zakat is distributed evenly among the poor it can be assumed that

$$
n_{t}^{p}=\left(\frac{1}{v}\right)\left(\zeta_{t}+\ell^{p} w_{t}\right)-1
$$

where the factor $v$ can be given the interpretation of the income required to ensure that the survival rate is just high enough to keep the number of poor constant.

\footnotetext{
${ }^{3}$ It can be seen that equal division gives the young poor greater income in total than the old poor. This may seem to favor the young, until it is observed that the young are raising children so have greater needs than the old.
} 
It is assumed the firms in the economy are competitive and all produce with the same constant returns to scale technology. Let $K_{t}$ be the capital stock in period $t$ and $L_{t}$ be aggregate supply of efficiency units of labor. Defining the per capita variables $y_{t}=\frac{Y_{t}}{L_{t}}$ and $k_{t}=\frac{K_{t}}{L_{t}}$, it follows that $y_{t}=f\left(k_{t}\right)$. The profit-maximizing use of inputs determines the factor rewards

$$
f\left(k_{t}\right)-k_{t} f^{\prime}\left(k_{t}\right)=w_{t},
$$

and

$$
f^{\prime}\left(k_{t}\right)=r_{t} .
$$

The equilibrium of an overlapping generations economy can be interpreted either as the time path of the endogenous variables or as the steady state in which all per capita variables are constant. We find it worthwhile to consider both of these concepts in what follows. In this model equilibrium can be expressed in terms of two state variables: the capital-labor ratio and the ratio of poor to rich in the population. The time path of the endogenous variables is described by a pair of non-linear difference equations that determines the transition of the state variables from one period to the next. The steady state is obtained by determining the fixed point of these non-linear difference equations.

Equilibrium in the capital market is achieved when capital demand in $t+1$ is equal to saving in $t$. Since it is only the rich that save this equilibrium condition can be written

$$
K_{t+1}=W_{t}-X_{t, t}^{r},
$$

where $W_{t}=N_{t}^{r} \int_{\underline{\sigma}}^{\bar{\sigma}} w_{t} \ell^{r}(\sigma) f(\sigma) d \sigma$ and $X_{t, t}^{r}=N_{t}^{r} \int_{\underline{\sigma}}^{\bar{\sigma}} x_{t, t}^{r}(\sigma) f(\sigma) d \sigma$. The total quantity of labor in period $t+1$ is

$$
L_{t+1}=N_{t}^{r} \int_{\underline{\sigma}}^{\bar{\sigma}} \ell^{r}(\sigma) f(\sigma) d \sigma+N_{t+1}^{p} \ell^{p} .
$$

Combining (9) and (10) equilibrium in the capital market can be expressed in term of the capital-labor ratio as

$$
k_{t+1}=\frac{N_{t}^{r} \int_{\underline{\sigma}}^{\bar{\sigma}} w_{t} \ell^{r}(\sigma) f(\sigma) d \sigma-N_{t}^{r} \int_{\underline{\sigma}}^{\bar{\sigma}} x_{t, t}^{r}(\sigma) f(\sigma) d \sigma}{N_{t+1}^{r} \int_{\underline{\sigma}}^{\bar{\sigma}} \ell^{r}(\sigma) f(\sigma) d \sigma+N_{t+1}^{p} \ell^{p}} .
$$

Now define the proportion of poor to rich at time $t$ by $\rho_{t} \equiv \frac{N_{t}^{p}}{N_{t}^{p}}$ and use (5) and (6) to obtain

$$
k_{t+1}=\frac{w_{t} \bar{\ell}^{r}-\bar{x}_{t, t}^{r}}{\left[1+n^{r}\right] \bar{\ell}^{r}+\frac{\ell^{p} \rho_{t}}{v}\left[\frac{\bar{z}_{t}}{\left[1+n^{r}\right] \rho_{t}+\rho_{t-1}}+\ell^{p} w_{t}\right]},
$$


where a bar denotes the mean of the variable. Equation (12) is the non-linear difference equation that updates the capital stock from $t$ to $t+1$. The significant difference to the standard overlapping generations model is that this equation also involves the endogenous variable $\rho_{t}$ and the value of the capital stock from $t-1$.

A second non-linear difference equation now has to be obtained to describe the time path of $\rho_{t}$. This is derived by taking the time path of the number of poor consumers relative to the number of rich consumers

$$
\frac{N_{t+1}^{p}}{N_{t+1}^{r}}=\frac{\left[1+n_{t}^{p}\right]}{\left[1+n^{r}\right]} \frac{N_{t}^{p}}{N_{t}^{r}}
$$

Using (5), and (6), this can be written

$$
\rho_{t+1}=\frac{1}{v\left[1+n^{r}\right]}\left[\frac{\bar{z}_{t}}{\left[1+n^{r}\right] \rho_{t}+\rho_{t-1}}+\ell^{p} w_{t}\right] \rho_{t} .
$$

The pair of equations (12) and (14) constitute the system of non-linear difference equations that determine the time paths of the endogenous variables $\left\{k_{t}\right\}$ and $\left\{\rho_{t}\right\}$. Given $\left\{k_{t}\right\}$ the time time paths of the factor prices are obtained from (7) and (8). Finally, consumption demands and zakat provision follow from the individual consumer decisions.

The steady state is achieved when all per capita variables are constant. In addition, the growth rate of the poor population must be equal to the growth rate of the rich population. If this were not the case then one population group would eventually become insignificant in size relative to the other. The steady state is a pair $\left\{k^{*}, \rho^{*}\right\}$ that simultaneously solve (12) and (14).

\section{Modeling zakat}

This section describes three alternatives forms of preferences that capture the motives for providing zakat. The key feature of zakat, as emphasized in the discussion of Section 2, is that it is voluntary. An analysis of the consequences of zakat therefore needs to model explicitly the motive for giving.

Section 2 identified the two reasons for giving that have been discussed in previous literature. The first explanation is that givers of zakat expect gratitude in return. The idea of gratitude suggests that there is a utility payoff from giving. The closest existing model to this situation is that of warm-glow giving where the size of donation enters as an argument of utility. The second explanation is that zakat is provided because it is a religious commitment. In this case there need not be any utility payoff from providing zakat. Instead, what can support a religious commitment is the occurrence of a utility loss if the religious commitment is not met. Such a loss can arise through feelings of guilt or shame about not acting in the appropriate manner. It is precisely such feelings that the social custom model has been designed to represent.

We now describe how we place these two forms of preferences, and a combination of the two, into the overlapping generations economy described above. 
This involves a description of the preferences, the resulting decision problem, and the characteristics of the population of rich consumers.

\subsection{Warm-glow}

The warm-glow model of giving assumes an act of charity delivers a private utility payoff. There are many potential explanations of what drives the private payoff. In the context of zakat it may be because of the observation of the improved living standards of the poor, or from the feeling of pleasure at fulfillment of a religious obligation, or directly from the deriving pleasure from the gratitude of recipients (where the recipient can be interpreted as the zakat collector or the ultimate recipient of charity). For our modelling the source of the warm glow is not too significant; what matters for the current analysis is the strength of the warm-glow and its implications for capital accumulation.

Before proceeding there are two points that should be noted in connection with the warm-glow interpretation. First, it has been observed that there are specified rates of zakat on different forms of wealth holding. This may seem inconsistent with the warm-glow model. It should be stressed that since payment is voluntary these rates have to be treated as guidance about the correct level of payment rather than as the precise determinant of payment. The actual payment can be less, or more, than the amount determined by the accepted rate. Different religious interpretations also lead to different rates. Secondly, the model we describe can be applied more generally as one of charitable giving and, hence, can provide insight into how charity affects capital accumulation. The only special feature of the model is that we follow the practice of zakat by insisting upon the charitable donations being transferred directly as payments to the poor members of society. In a general model of charity it would be possible to conceive of alternative uses of charitable funds.

The model of warm-glow giving is based on the utility function for the rich

$$
U^{r}=U\left(x_{t, t}^{r}, x_{t, t+1}^{r}, z_{t+1}\right) .
$$

The appearance of the zakat payment, $z_{t+1}$, as an argument of utility represents the warm-glow derived from giving to zakat. It is also assumed that all the rich consumers have the same level of labor supply. This is fixed at $\ell^{r}$. Under this assumption the characteristics vector for a rich consumer is $\sigma=\ell^{r}$ and the typespace is the single point $\Sigma=\left\{\ell^{r}\right\}$. The utility function in (15) is maximized subject to the intertemporal budget constraint

$$
w_{t} \ell^{r}=x_{t, t}^{r}+\frac{x_{t, t+1}^{r}}{1+r_{t+1}}+\frac{z_{t+1}}{1+r_{t+1}} .
$$

With this model of warm-glow giving the level of zakat is a free choice variable.

\subsection{Social custom}

A second explanation of voluntary giving is that it arises as the outcome of a social custom. The basic idea of a social custom is that those who do not act 
in the socially-approved manner suffer a utility loss relative to those who do act correctly (Myles and Naylor, 1996). If the population is heterogenous with respect to the size of this utility loss then those for which it is large will abide by the social custom whereas those for which it is small will not. This process partitions the population, with the point of partition endogenously determined in equilibrium.

This idea is now applied to zakat by assuming that the rich can choose whether or not to provide zakat. If they choose not to provide then they suffer a loss of utility as a consequence of the social custom. The choice of whether to provide is determined by comparing the utility obtained with no provision of zakat (higher consumption but a loss through the social custom) to the utility obtained when zakat is provided (lower consumption but no social custom loss). Whichever of these utilities is larger determines the chosen action.

Each rich consumer is characterized by a value of the utility loss from breaking the social custom. Denote the utility loss from breaking the social custom by $\chi$. The assumption that all rich consumers have the same labor supply is retained. The vector of characteristics describing a rich consumer is now $\sigma=\left(\ell^{r}, \chi\right)$ and the type-space is $\Sigma=\ell^{r} \times[\chi, \bar{\chi}]$.

Consider first the decision problem of a rich consumer who chooses to provide zakat. It is assumed that if a consumer chooses to provide zakat then the payment is made in accordance with the rules. If $\phi$ is the rate of zakat on wealth the optimization for a zakat payer is

$$
\max _{\left\{x_{t, t}^{r}, x_{t, t+1}^{r}\right\}} U\left(x_{t, t}^{r}, x_{t, t+1}^{r}\right) \text { s.t. } w_{t} \ell^{r}=x_{t, t}^{r}+\frac{x_{t, t+1}^{r}}{\left[1+r_{t+1}\right][1-\phi]} .
$$

Denote the maximum value function for the optimization in (17) by $V_{z}\left(w_{t}, r_{t+1}, \phi\right)$. The decision problem of a rich consumer who does not provide zakat is

$$
\max _{\left\{x_{t, t}^{r}, x_{t, t+1}^{r}\right\}} U\left(x_{t, t}^{r}, x_{t, t+1}^{r}\right)-\chi \text { s.t. } w_{t} \ell^{r}=x_{t, t}^{r}+\frac{x_{t, t+1}^{r}}{1+r_{t+1}} .
$$

The maximum value function for the this optimization is denoted $V_{0}\left(w_{t}, r_{t+1}\right)-$ $\chi$. Comparing the two maximum value functions, the consumer will provide zakat if $V_{z}\left(w_{t}, r_{t+1}, \phi\right)>V_{0}\left(w_{t}, r_{t+1}\right)-\chi$, but not provide zakat otherwise.

For given values of $w_{t}, r_{t+1}$ and $\phi$ there will be value $\chi_{t+1}^{*}$ at which

$$
V_{z}\left(w_{t}, r_{t+1}, \phi\right)=V_{0}\left(w_{t}, r_{t+1}\right)-\chi_{t+1}^{*} \text {. }
$$

This value of $\chi_{t+1}^{*}$ partitions the population of the rich so that those with $\chi<\chi_{t+1}^{*}$ do not pay zakat at time $t+1$ but those with $\chi>\chi_{t+1}^{*}$ pay zakat. Given this partition of the rich, the levels of first- and second-period consumption are then determined by (17) for a zakat payer and (18) for a non-payer.

\subsection{Combined model}

The third representation of preferences combines the warm-glow and the social custom models. The basic assumption is that the social custom utility is obtained by providing the minimum required level of zakat. But, since the amount 
of zakat provided is voluntary, a warm-glow is obtained by paying in excess of the minimum level.

For this representation of preferences the rich consumers differ in both the value of the social custom utility loss and in the quantity of labor they can provide. Since labor is measured in efficiency units the variation in labor supply among the rich can be attributed to skill differences. Hence, each consumer is characterized by a vector $\sigma=\left(\ell^{r}, \chi\right)$ and the type-space is described by the set $\Sigma=\left[\underline{\ell}^{r}, \overline{\ell^{r}}\right] \times[\underline{\chi}, \bar{\chi}]$.

A rich consumer who does not provide zakat suffers a utility loss of $\chi$ so the level of utility is $U^{r}=U\left(x_{t, t}^{r}, x_{t, t+1}^{r}\right)-\chi$, with corresponding value function

$$
V_{0}\left(w_{t}, r_{t+1}, \ell^{r}\right)-\chi \equiv \max _{\left\{x_{t, t}^{r}, x_{t, t+1}^{r}\right\}}\left\{\begin{array}{c}
U\left(x_{t, t}^{r}, x_{t, t+1}^{r}\right)-\chi \\
\text { s.t. } w_{t} \ell^{r}=x_{t, t}^{r}+\frac{x_{t, t+1}^{r}}{1+r_{t+1}}
\end{array}\right\}
$$

The utility for a consumer who does provide zakat utility includes a warm glow from providing in excess of the minimum; hence $U^{r}=U\left(x_{t, t}^{r}, x_{t, t+1}^{r}\right)+\Gamma\left(\xi_{t+1}\right)$ where $z_{t+1}=\xi_{t+1}+\phi(1+r) s_{t}$. It is assumed that $\Gamma(0)=0$ and $\Gamma^{\prime}\left(\xi_{t+1}\right)>0$. The value function when zakat is given is defined by

$$
V_{z}\left(w_{t}, r_{t+1}, \phi, \ell^{r}\right)=\max _{\left\{x_{t, t}^{r}, x_{t, t+1}^{r}, z_{t+1}\right\}}\left\{\begin{array}{c}
U\left(x_{t, t}^{r}, x_{t, t+1}^{r}\right)+\Gamma\left(\xi_{t+1}\right), \\
\text { s.t. } w_{t} \ell^{r}=x_{t, t}^{r}+\frac{x_{t, t+1}^{r}+\xi_{t+1}}{\left[1+r_{t+1}\right][1-\phi]}, \\
\xi_{t+1} \geq 0 .
\end{array}\right\} .
$$

If $U\left(x_{t, t}^{r}, x_{t, t+1}^{r}\right)$ and $\Gamma\left(\xi_{t+1}\right)$ are concave then $\xi_{t+1}$ is increasing in $w_{t} \ell^{r}$ whenever it is strictly positive. Consequently, there is a value $\hat{\ell}^{r}$ such that if $\ell^{r} \leq \hat{\ell}^{r}$ then $z_{t+1}=\phi\left(1+r_{t+1}\right) s_{t}$ and if $\ell^{r}>\hat{\ell}^{r}$ then $z_{t+1}>\phi\left(1+r_{t+1}\right) s_{t}$. Rich consumers with labor supply above $\hat{\ell}^{r}$ provide zakat above the minimum (if they choose to provide at all) and benefit from the warm-glow. The value of $\hat{\ell}^{r}$ is independent of $\chi$, so the attainment of the warm-glow is separate from the decision on whether or not to provide.

For a given value of $\ell^{r}$ the critical value of the social custom utility loss is defined by

$$
V_{z}\left(w_{t}, r_{t+1}, \phi, \ell^{r}\right)=V_{0}\left(w_{t}, r_{t+1}, \ell^{r}\right)-\chi .
$$

The right-hand side of (22) is linear in $\chi$ and the left-hand side independent of $\chi$, so there exists a function $\chi=\chi\left(\ell^{r}\right)$ such that a rich consumer with labor supply $\ell^{r}$ will provide zakat if $\chi>\chi\left(\ell^{r}\right)$ but will not provide otherwise. Notice that for given $\chi$ there need not be a unique solution in $\ell^{r}$ to (22): the equation involves the intersections of two concave functions so that it is possible for them to intersect multiple times. If $\chi>\chi\left(\ell^{r}\right)$ the level of $z_{t+1}$ is determined by the optimization program (21). Conversely, if $\chi \leq \chi\left(\ell^{r}\right)$ then consumption is determined by the optimization program (20)

This reasoning implies that consumers with labor supply $\ell^{r} \in\left[\underline{\ell}^{r}, \widehat{\ell}^{r}\right]$ and $\chi>\chi\left(\ell^{r}\right)$ will provide zakat equal to $\phi\left(1+r_{t+1}\right) s_{t}$ and will obtain no warm-glow. Those with labor supply $\ell^{r} \in\left(\widehat{\ell}^{r}, \ell^{r}\right]$ and $\chi>\chi\left(\ell^{r}\right)$ will provide zakat to a level 


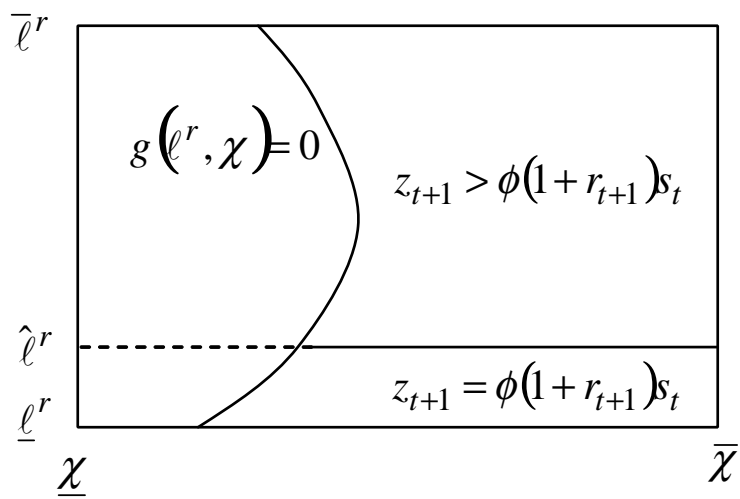

Figure 1: Division of population: warm glow and social custom

$z_{t+1}>\phi\left(1+r_{t+1}\right) s_{t}$ and will derive a warm-glow. These results are summarized in Figure 1 which illustrates the separation of the population. The key point of the figure is that there need not be monotonicity in the relation between $\chi$ and $\ell^{r}$. The aggregate values for the endogenous variables are computed by integrating over the population taking into account the critical values that separate the different behavior regions and, consequently, different consumption demands and level of zakat provision.

\section{Results}

The consequences of the institution of zakat for capital accumulation and growth in the overlapping generations economy are now investigated using a simulation analysis. This emphasis is in line with the literature discussed in Section 1 that has focused upon the question of whether zakat increases capital accumulation. The simulations explore the three different forms of preferences and also contrast zakat to standard wealth taxation.

The production function employed in all the simulations is $f\left(k_{t}\right)=k_{t}^{a}$, with $a=0.36$. The other parameter values that remain constant are: $\ell^{p}=0.1$, and $n^{r}=0.05$. The initial value of the capital-labor ratio is $k_{0}=0.01$ and the initial ratio of poor to rich is $\rho_{0}=0.05$.

\subsection{Warm-glow}

The simulation of the warm-glow model is based on a Cobb-Douglas utility function for the rich

$$
U^{r}=\left[x_{t, t}^{r}\right]^{\alpha}\left[x_{t, t+1}^{r}\right]^{\beta}\left[z_{t+1}\right]^{\gamma},
$$

with parameters values $\alpha+\beta+\gamma=0.75$. All simulations have $\alpha=\beta$, so when $\gamma$ is varied $\alpha$ and $\beta$ are changed proportionately. The labor supply of the rich 
is fixed at $\ell^{r}=1$ and the growth rate of the poor has parameter $v=1$

The first step is to determine the relationship between the growth rate of output and the relative concern for giving zakat as measured by the value of $\gamma$. The process used is to compute the mean growth rate of output per capita, $\bar{g}_{y}$, for the first five generations. ${ }^{4}$ Table 3 shows that an increase in the concern for zakat raises the growth rate of output. The basic mechanism behind this result is clear: a greater concern for zakat increases saving so capital is accumulated more quickly and output rises faster. But this is not full story since the population structure is also changing. In this case, the proportion of poor does not grow as fast the capital stock, so the output-labour ratio rises.

Table 3: Concern for zakat and the mean growth rate

\begin{tabular}{|l|l|l|l|l|l|}
\hline$\gamma$ & 0.05 & 0.1 & 0.15 & 0.2 & 0.25 \\
\hline $\bar{g}_{y}$ & 8.019 & 8.294 & 8.554 & 8.798 & 9.029 \\
\hline
\end{tabular}

The next step is to compare the steady-state level of the capital-labor ratio and the proportion of poor to rich for different values of the preference for giving zakat. The results are summarized in Table 4 . It can be seen the steady-state levels $k^{*}$ and $\rho^{*}$ increase with $\gamma$. Within the context of the model these results demonstrate that the institution of zakat raises the steady-state value of the capital-labor ratio. Not surprisingly, a greater concern for giving zakat leads to more redistribution and permits a larger population of poor consumers to be sustained.

Table 4: The steady-state

\begin{tabular}{|l|l|l|l|l|l|l|l|l|}
\hline$\gamma$ & 0.05 & 0.1 & 0.15 & 0.2 & 0.25 & 0.3 & 0.35 & 0.4 \\
\hline$k^{*}$ & 0.1724 & 0.1891 & 0.2062 & 0.2238 & 0.2418 & 0.2602 & 0.2789 & 0.2980 \\
\hline$\rho^{*}$ & 0.0241 & 0.0484 & 0.0729 & 0.0976 & 0.1226 & 0.1480 & 0.1737 & 0.1997 \\
\hline
\end{tabular}

To provide a point of comparison it is interesting to compare the properties identified for the economy with zakat as a warm-glow to an economy that employs a traditional wealth tax to conduct redistribution. This seems an appropriate comparison since zakat is often interpreted as a voluntary tax on wealth. It is important to stress that the numerical values should not be compared across the systems (since a like-for-like comparison cannot be uniquely identified) but it is valid to compare the qualitative properties of the systems.

For the wealth tax the warm glow is no longer relevant so the adjustment $\alpha^{\prime}=\alpha+\frac{\gamma}{2}, \beta^{\prime}=\beta+\frac{\gamma}{2}$ is adopted and the Cobb-Douglas utility function used without the warm-glow. The budget constraint for the wealth tax is

$$
\ell_{t, t}^{r}=x_{t, t}^{r}+\frac{x_{t, t+1}^{r}}{\left(1+r_{t+1}\right)(1-\tau)},
$$

so wealth accumulated is taxed at rate $\tau$ in the second period of life. It is assumed that the poor do not accumulate wealth, and that the tax revenue

\footnotetext{
${ }^{4}$ After five generations the economy is close to its steady state where growth in per capita output is zero unless there is exogenous technical progress. Interpreted literally, five generations represents approximtely 125 years.
} 
raised from the rich is used to fund a payment to the poor. This payment is divided equally among all the poor.

Table 5 shows the steady-state values of the capital-labor ratio and the growth of the proportion of poor to rich with the wealth tax. The interesting feature is that the increase in tax rate reduces the steady state level of capital. Hence, increasing the wealth tax to increase assistance to the poor reduces the steady-state capital-labor ratio. This is the converse effect to encouraging zakat through a stronger warm-glow effect. This result is explained by the fact that a wish to give zakat encourages wealth to be accumulated whereas a wealth tax discourages wealth accumulation.

Table 5: Wealth tax

\begin{tabular}{|l|l|l|l|l|l|l|l|l|}
\hline$\tau$ & 0.05 & 0.1 & 0.15 & 0.2 & 0.25 & 0.3 & 0.35 & 0.4 \\
\hline$k^{*}$ & 0.1561 & 0.1559 & 0.1558 & 0.1557 & 0.1556 & 0.1555 & 0.1554 & 0.1553 \\
\hline$\rho^{*}$ & 0.0046 & 0.0093 & 0.0139 & 0.0186 & 0.0232 & 0.0279 & 0.0326 & 0.0372 \\
\hline
\end{tabular}

These results have demonstrated that with the warm-glow interpretation a stronger institution of zakat increases the capital-labor ratio. Increased concern for giving zakat can raise the growth rate of output and the steady-state levels of the capital-labor ratio and the ratio of poor to rich. In contrast, increased redistribution financed by a wealth tax reduces the capital-labor ratio.

\subsection{Social Custom}

The social custom model provides a different motivation for providing zakat. The central feature of this model is the utility loss from breaking the social custom.

The simulation assumes a Cobb-Douglas utility function

$$
U^{r}=\left[x_{t, t}^{r}\right]^{\alpha}\left[x_{t, t+1}^{r}\right]^{\beta},
$$

with parameters $\alpha=\beta=0.375$. Each rich consumer is characterized by the utility loss, $\chi$, that they suffer if the break the social custom. The utility loss is assumed to be uniformly distributed on the interval $[0,0.1]$. Other parameter values are identical to those in the simulation of the warm-glow.

Table 6 shows the effect of raising the rate of zakat, $\phi$. The steady-state capital-labor ratio is decreased as $\phi$ increases but the quantitative size of the effect is very small. The proportion of the poor increases with $\phi$. The proportion of the rich that participate in the social custom is denoted by $P^{*}$. The effect of raising the rate of zakat is to reduce participation so that a higher value of $\phi$ results in a smaller proportion of the population providing zakat. This reduced participation offsets the effect of increasing $\phi$ on the amount of zakat raised. The mean growth rate is non-monotonic with respect to $\phi$.

Table 6: Increasing the rate of zakat 


\begin{tabular}{|l|l|l|l|l|l|l|}
\hline$\phi$ & 0.05 & 0.1 & 0.15 & 0.2 & 0.25 & 0.3 \\
\hline$k^{*}$ & 0.1560 & 0.1558 & 0.1557 & 0.1556 & 0.1555 & 0.1555 \\
\hline$\rho^{*}$ & 0.0080 & 0.0149 & 0.0205 & 0.0248 & 0.0277 & 0.0292 \\
\hline$P^{*}$ & 0.9342 & 0.8663 & 0.7959 & 0.7230 & 0.6471 & 0.5680 \\
\hline $\bar{g}_{y}$ & 6.436 & 6.435 & 6.434 & 6.434 & 6.434 & 6.435 \\
\hline
\end{tabular}

This analysis of zakat as a social custom shows that participation in the provision of zakat changes with the rate of zakat to leave the capital-labor ratio barely affected. With this formulation changing $\phi$ has little effect upon capital accumulation. Hence, additional zakat can be obtained to redistribute to the poor without unduly affecting the capital-labor ratio. An increased rate of zakat discourages participation despite the social custom.

\subsection{Combined model}

The results for the warm-glow model show that a greater concern for giving zakat raises the steady-state level of the capital-labor ratio. Conversely, in the social custom model an increase in the rate of zakat reduces (though not by much) the steady-state capital-labor ratio. The alternative interpretations of the motive for giving zakat therefore lead to different predictions. This provides the motivation for considering a more general model that combines the two.

The simulation of the economy is based on a quasi-linear utility function for rich consumers who contribute to zakat

$$
U_{t}^{r}=\left[x_{t, t}^{r}\right]^{\alpha}\left[x_{t, t+1}^{r}\right]^{\beta}+\gamma \xi_{t+1},
$$

where $\xi_{t+1}$ is the contribution to zakat above the recommended level. A noncontributor has $\xi_{t+1}=0$ and suffers a utility loss of $\chi$. The minimum and maximum values of labor supply are $\underline{\ell}^{r}=1$ and $\bar{\ell}^{r}=10$, and the upper and lower values of the social custom are $\chi=0, \bar{\chi}=0.5$. It is also assumed that $v=2$.

Table 7 details the effect of increasing $\phi$. The important observation is that the capital-labor ratio is reduced as the rate of zakat increases. This conforms with the outcome in the economy with just a social custom. The value of $P^{*}$ decreases as the rate of zakat increases so there is less participation in the provision of zakat. Despite this, the proportion of the poor increases. This is the explanation for the capital-labor ratio falling as the rate of zakat increases. The mean growth rate of output also falls as $\phi$ increases.

Table 7: Increasing the rate of zakat $(\gamma=0.15)$

\begin{tabular}{|l|l|l|l|l|l|l|}
\hline$\phi$ & 0.05 & 0.1 & 0.15 & 0.2 & 0.25 & 0.3 \\
\hline$k^{*}$ & 0.1561 & 0.1560 & 0.1559 & 0.1559 & 0.1558 & 0.1557 \\
\hline$\rho^{*}$ & 0.0234 & 0.0426 & 0.0609 & 0.0770 & 0.0908 & 0.1020 \\
\hline$P^{*}$ & 0.9648 & 0.9284 & 0.8905 & 0.8500 & 0.8097 & 0.7664 \\
\hline $\bar{g}_{y}$ & 7.815 & 7.801 & 7.789 & 7.777 & 7.763 & 7.749 \\
\hline
\end{tabular}


The final simulation considers the effect of increasing the utility obtained from the warm-glow upon the capital-labor ratio. Table 8 shows that the steadystate value of the capital-labor ratio falls as $\gamma$ increases. This differs from the result obtained from the economy with only the warm-glow. The reason for this is the rapid increase in the the proportion of poor as more rich participate in the social custom of zakat. Unlike the basic warm-glow model, an increase in $\gamma$ reduces the mean growth rate of output.

Table 8: Enhancing the warm-glow $(\phi=0.2)$

\begin{tabular}{|l|l|l|l|l|l|l|}
\hline$\gamma$ & 0.05 & 0.1 & 0.15 & 0.2 & 0.25 & 0.3 \\
\hline$k^{*}$ & 0.1559 & 0.1559 & 0.1559 & 0.1549 & 0.1539 & 0.1533 \\
\hline$\rho^{*}$ & 0.0589 & 0.0599 & 0.0609 & 0.2958 & 0.5275 & 0.6431 \\
\hline$P^{*}$ & 0.8684 & 0.8796 & 0.8905 & 0.9446 & 0.9832 & 0.9938 \\
\hline $\bar{g}_{y}$ & 7.7195 & 7.7194 & 7.789 & 7.769 & 7.732 & 7.713 \\
\hline
\end{tabular}

The results of this section have been derived for an economy where the giving of zakat involves both a warm-glow and a social custom. An increase in the rate of zakat is met with a reduction in the participation in the social custom and an increase in the proportion of the poor sufficient to reduce the capital-labor ratio. In contrast, an increase in the concern for the warm-glow raises participation in the social custom. The steady-state capital-labor ratio falls nonetheless due to an increase in the proportion of the poor. These results show that the rate of zakat can be raised without excessive damage to the capital-labor ratio and that participation in zakat can be increased if effort is devoted to emphasizing the warm-glow. The effect of both policies is to raise the relative level of support given to the poor which increases the proportion of poor in the population.

\section{Conclusions}

The paper has considered the effects of the institution of zakat on capital accumulation and growth. Zakat has been interpreted as a voluntary system of redistribution supported by the concept of religious obligation. It has been modeled as an alternative to redistribution financed by statutory taxation. Two alternative motivations for providing a voluntary payment of zakat have been analyzed. The warm-glow assumes that zakat gives a private utility return. The social custom assumes that there is a utility loss to not paying. These motives for giving zakat have been embedded within an overlapping generations model with heterogenous consumers and endogenous population growth.

With a warm glow the stronger is the preference for zakat the faster output grows and the higher is the capital-labor ratio in the steady state. This provides a sense in which the previous claims about zakat raising the capital stock are correct. The results from the social custom model are somewhat different. In this case a higher the rate of zakat slows growth and the lowers the steady state capital-labor ratio. A higher rate also reduces participation in the social custom. These results are modified in a model that combines both the warm 
glow of giving and the social custom. Both a stronger preference for the warmglow and an increase in the rate of zakat reduce the mean rate of growth and the steady-state capital labor ratio but do achieve an increase in redistribution and a consequent increase in the proportion of the poor in the population. This variety of effects makes clear that care must be taken with interpreting any claim that the institution of zakat increases, or reduces, the capital stock. Since these claims are based on simulation analysis they are obviously limited in generality. However, the framework we have used has proved sufficiently flexible to generate an interesting range of outcomes.

The paper has explored two senses in which the question of a strengthening of the institution of zakat can be interpreted. The results show that increasing the perception of the warm-glow from providing zakat is more effective than raising the rate of zakat because an increase in rate reduces participation. In addition, we would like to claim that the analysis has demonstrated that the economic consequences of a religious obligation can be addressed by adapting existing economic models. The warm-glow and the social custom can explain voluntary contribution, and can be interpreted in terms that accord with the basic religious roots of the institution of zakat.

\section{References}

Ahmad, K. (1980) "Economic Development in an Islamic Framework", in Studies in an Islamic Economics by Ahmad, K., Ed., Leicester: The Islamic Foundation.

Alexander, L., Coleman, R., Bennett, E., Dam, K. W., Delaney, H.R.J. and Dennis, K. O. (1997) Giving better - giving smarter: The report of the National Commission on Philanthropy and Civic Renewal, Washington: National Commission on Philanthropy and Civic Renewal.

Al-Abdin, A.Z. (1997) "Zakat and the alleviation of poverty in the Muslim world" Hamdard Islammicus 20, 65-82.

Al-Qardawi, Y. (1997) Fiqh-Az-Zakat- A Comparative Study, English Translation by Monzer Kahf, London: Dar-Al Taqwa Ltd.

Andreoni, J. (1990) "Impure altruism and donations to public goods: A theory of warm-glow giving" Economic Journal 100, $464-477$.

Chapra, M. U. (1992) Islam and the Economic Challenge, Leicester: The Islamic Foundation.

El-Ashkar, A. (1987) The Islamic Business Enterprise, London: Croom Helm.

Iqbal, M. (1985) "Zakat, moderation and aggregate consumption in an Islamic economy" Journal of Research in Islamic Economics 3, 45-61.

Kahf, M. (1980) "A Contribution to the Theory of Consumer Behaviour in an Islamic Society", in Studies in Islamic Economics by Ahmad, K., Ed., Leicester: The Islamic Foundation.

Kahf, M., (1997) Economics of Zakat Book of Reading No.2, Jeddah: Islamic Development Bank.

Kahf, M. (1999) "The Performance of the Institution of Zakah in Theory and Practice" Presented at the International Conference on Islamic Economics 
towards the 21st century, Kuala Lumpur, 1999.

Kamali, M.H. (1999) Freedom Equity and Justice in Islam, Petaling Jaya: Ilmiah Publishers Sdn Bhd.

Khan, M.F. (1984) "Macro consumption function in an Islamic framework" Journal of Research in Islamic Economics 1, 1-24.

Kuran, T. (2006) Islam and Mammon: The Economics Predicaments of Islamism, Oxfordshire: Princeton University Press.

Mannan, M.A. (1986) Islamic Economics: Theory and Practice, London: Hodder and Stoughton.

Myles, G.D. and Naylor. R.A. (1996) "A model of tax evasion with group conformity and social customs" European Journal of Political Economy 12, 49 -66 .

Rahman, M. (2003) Zakat Calculation: Primarily Based on Fiqh-uz-Zakat by Yusuf-al-Qardawi, Leicester: The Islamic Foundation.

Shaik, A.A. (1980) "Concept of Zakat: A Survey of Quranic Texts and their Explanations in Shariah and Contemporary Economics", in Some Aspects of the Economics of Zakat by Zaman, M.R., Ed., Indiana: American Trust Publications.

Siddiqi, S. A. (1979) "Zakat", in Public Finance in Islam by Sh Muhammad Ashraf, Ed., Lahore: Islamic Publications.

Zaman, R. (1980) "Policy Implications of Introducing Zakah into Bangladesh and into Saudi Arabia", in Some Aspects of the Economics of Zakat by Zaman, M.R , Ed., Indiana: American Trust Publications.

Zayas, F.G (1960) The Law and Philosophy of Zakat, Damascus: Al-Jadidah Press. 